\title{
GOING ONLINE: THE INFLUENCE OF COVID-19 ON STUDENT'S LEARNING EXPERIENCE
}

\author{
Răzvan-Andrei CORBOȘa ${ }^{*}$,Ovidiu-Iulian BUNEA ${ }^{b}$, Andreea-Ileana ZAMFIR ${ }^{c}$, \\ Ana-Alexandra GORA ${ }^{d}$ \\ ${ }^{a, b, c, d}$ Bucharest University of Economic Studies, Romania
}

DOI: $10.24818 / \mathrm{IMC} / 2020 / 02.11$

\begin{abstract}
The COVID-19 pandemic has caused an unprecedented crisis in almost all areas. In the field of education, this pandemic has led to the closure of the face-to-face activities of educational institutions and the rethinking of the entire teaching-learning process to move education to the online environment. In the context of the COVID-19 pandemic, the purpose of this article is to identify students' satisfaction with the online learning experience and the extent to which the university and their teachers have adapted to the new challenges of online education. Data were collected from 301 students using an online questionnaire. The main results indicate that from the perspective of students, both the university where they study and their professors, have managed to adapt to the requirements imposed by the transition of teaching-learning activities in the online environment, which has had a positive effect on the learning experience, as shown by the regression analysis used in this research. These results show that the research brings several theoretical contributions by strengthening the results obtained through other studies conducted in the field of education in the context of the COVID-19 pandemic, as well as a number of practical contributions, helping decision makers in the education system to make better decisions regarding teaching environments, educational strategies and teaching activities, with a significant impact on students' learning experience. Preparedness and adaptedness of both the university and its professors and the choice of a single adequate online platform, positively influence students' online learning experience.
\end{abstract}

KEYWORDS: COVID-19, emergency, higher education, student satisfaction, online teaching,

\section{INTRODUCTION}

On March 11, 2020, the World Health Organization (WHO, 2020) declared that the COVID-19 epidemic could be characterized as a pandemic. Since its inception, the COVID-19 pandemic has affected almost all aspects of society and daily life, people being put in the position to learn to organize their communication and interaction in a new way.

To prevent the spread of the new virus, the authorities have imposed multiple measures. One of the first and most important measures recommended by the authorities was social distancing, which requires a new way of working: teleworking. The education system was no exception to this measure, with the COVID-19 pandemic leading to the closure of schools and the transition to online education. In this context, both universities and professors had to adapt and switch to online teaching.

Thus, this article aims to analyze students' perceptions of how prepared it was and to what extent the university where they study adapted to the changes imposed by the COVID-19 pandemic.

\footnotetext{
${ }^{*}$ Corresponding author. E-mail address: razvan.corbos@man.ase.ro
} 
Moreover, through this article we aim to study students' perceptions about the extent to which professors have adapted to online teaching and about the online platforms used to facilitate teacherstudent interaction. Finally, the present research aims to identify the influences between the degree of adaptation of the university and professors to the online environment and the way students perceive the online learning experience.

This paper is based on a survey of students and addresses the following research questions:

RQ 1: How prepared was it and how well did the university where you study adapted to the changes imposed by the COVID-19 pandemic?

RQ 2: To what extent have teachers managed to adapt to online teaching and which are the platforms they use to facilitate teacher-student interaction?

RQ 3: How do students appreciate the online learning experience?

RQ 4: Which are the influences between the degree of adaptation of the university and teachers to the online environment on the online learning experience of students?

\section{LITERATURE REVIEW}

The COVID-19 pandemic affected all areas, including education, and once lockdowns were imposed, schools and universities were closed. Therefore, online courses have become a priority in continuing education (Rajab et al., 2020). According to Mishra et al. (2020), in the context of the COVID-19 pandemic, online education is a transition from the traditional method to a modern teaching-learning approach from classroom to ZOOM, from personal to virtual and from seminars to webinars.

As Hill and Fitzgerald (2020) state, the COVID-19 pandemic has required several major changes in education in terms of teaching environments, educational strategies, and teaching activities, with a significant impact on students' learning experience. The COVID-19 pandemic has come with a multitude of barriers and challenges for university communities around the world. One of the biggest challenges has been the sudden shift from face-to-face teaching practices to those entirely online. Here we must make the following remark, namely the differentiation that is made between online education and emergency remote teaching (Rapanta et al., 2020). Thus, when evaluating the level of preparation of the higher education institution for the new context created by the COVID-19 pandemic, we will take into account the fact that online education presupposes the pre-existence of a certain organizational infrastructure that allows the online teaching-learning process. On the other hand, emergency remote teaching is what the COVID-19 pandemic required and meant for all universities that did not have pre-existing online courses, a quick improvisation, without having a logistical and technological support suitable and guaranteed for this kind of activities (Rapanta et al., 2020). In addition to training to use appropriate technological tools, teachers also need pedagogical training (Rapanta et al., 2020). As the technological infrastructure to support online courses was lacking in most cases, universities focused more on supporting teachers in using the technological tools available and considered appropriate to go through this change.

Under these conditions, teachers face several major challenges in adapting to online teaching and ensuring a minimum of communication with students in order to support their learning and development (König et al., 2020). Teachers have made impressive efforts to adapt their work to the new teaching activities, and from their perspective, the main challenges and obstacles of online teaching are: lack of adequate infrastructure, lack of physical contact with their students, an additional amount of work needed to update their pre-existing teaching materials (Mișu, 2020).

In the context of the measures imposed by the COVID-19 pandemic, teaching-learning activities would not have been possible without the rigorous use of the various online teaching platforms. Thus, students also had to adapt to new teaching environments and learn to use different types of platforms, such as ZOOM, Google Classroom, etc., to continue the learning and development process. A study of several universities in Lebanon (Hamade, 2020) shows that online teaching and learning platforms face many barriers such as culture, cost, accreditation and various other challenges that need to be overcome. The same study indicated that educational institutions used Moodle, ZOOM and Google 
Classroom platforms, and in terms of student satisfaction with these platforms, ZOOM recorded the lowest level of satisfaction. Previous studies show that from a student perspective, the main challenges of online education imposed by the COVID-19 pandemic include in-person communication, student assessment, use of technology tools, experience in online education, pandemic-related anxiety and stress, time management, students' evaluations of faculty and technophobia (the fear of using technological tools like computers) (Rajab et al., 2020). Another study on the level of online class preparation in Bangladesh during the COVID-19 pandemic (Ramij \& Sultana, 2020) highlighted the main challenges faced by most students in the online education process: lack of adequate technological infrastructure, high cost of Internet connection, poor Internet speed, family income level and psychological pressure.

At the same time, examining the challenges facing professors and students at an Indian university in adapting the teaching-learning process during the COVID-19 pandemic, Mishra et al. (2020) identified the following significant online teaching challenges reported by teachers: (1) unstable network connection, and if students had switched off the cameras the connection would become more stable but the way of teaching was affected as professors had the feeling that they teach to a white wall; (2) lack of essential resources for students to join online classes; (3) lack of scope for meaningful interaction; (4) mechanical conduct of classes; (5) the range for innovative teaching (6) the inability to read on students' faces which led to difficulties in changing the teaching pattern. Moreover, through their study, Mishra et al. (2020) also identified a number of challenges of online learning experienced by students, including: lack of resources to participate in online courses; the lack of a conducive learning environment at home, with students stating that they were often distracted while attending classes by the people they lived with; the stressful situation in which the students were involved because online teaching-learning was a new experience for both them and the teachers. According to Osman (2020), adapting to the new teaching and learning environments adds an important new dimension to the teaching practicum, where the candidates are better prepared to work in both e-learning and face-to-face environments, which means that the teacher education program and the teaching practicum must be revised following the requirements of online teaching skills.

\section{RESEARCH METHODOLOGY}

\subsection{Research sample}

The theoretical model and the research questions were tested using a representative sample, made up of third year students from the Faculty of Management within the Bucharest University of Economic Studies. We chose a method of quantitative research, namely the opinion poll, using the questionnaire as a research tool. This questionnaire was applied between April and May 2020, online, through the Google Forms platform.

To determine a representative research sample, the literature (Boddy, 2016; Dell et al., 2002; Dupont \& Plummer, 1990; Singh \& Masuku, 2014; Weinberg \& Kleinman, 2003) provides several methods that we can use depending on the research topic, but also on other phenomena that can make their presence felt in the research process. Specifically, to establish a suitable representative sample for this research, we used a method that involves determining a representative sample based on statistical tables proposed by the authors Krejcie and Morgan (1970). Through these statistical tables, one can determine the size of the sample, provided that the statistical population is between 10 and 1.000 .000 observation units. The two authors used the following formula to determine the sampling dimension values:

$$
s=\frac{X^{2} N P(1-P)}{d^{2}(N-1)}+X^{2} P(1-P)
$$

Where:

$\mathrm{s}$ - required sample size; 
$X^{2}$ - the theoretical value of the chi-square test for a degree of freedom and a statistical significance level of 0,05 ;

$\mathrm{N}$ - the size of the investigated group;

$\mathrm{P}$ - parameter that expresses a specific share of the population;

$d^{2}$ - degree of accuracy.

Given that the total number of students in the third year was about 460, which represents the statistical population, according to the statistical tables proposed by Krejcie and Morgan (1970), a representative sample consists of 210 observation units. We managed to collect data from 301 respondents, which makes our research sample representative for third year students from the Faculty of Management at the Bucharest University of Economic Studies.

\subsection{Research questions and variables}

To answer the first three questions of the research, a series of graphs were analyzed and interpreted. With regard to the fourth question of the research, and more specifically, to determine the factors that influence students' online learning experience as a result of changes in university education, which took place due to the COVID-19 pandemic, we built a set of variables that we used to test the connections and the influences between them. Thus, we chose to use a multiple linear regression model to test these influences. There were nine independent variables, but only four of them had statistically significant influences and for this reason, in the continuation of our paper we will present in the regression model only these variables and their influences, respectively.

The independent and dependent variables were ${ }^{i}$ :

a) Independent:

- Perception of the extent to which the university was prepared for such a situation (UNP) - this variable describes the level at which students perceived that the university in which they study was prepared to move online (You consider that the university in which you study was prepared for such a situation);

- Perception of the extent to which the university has adapted to the new context (UNA) - this variable describes the level and degree to which students perceived that the university in which they study has adapted to the transition to the online environment (The university where you study has adapted well to the new context of online teaching);

- Preference for a single tool or a combination of e-learning tools (UNI) - this variable describes the extent to which students prefer a single tool or a combination of e-learning tools in order to have a pleasant e-learning experience (For a more enjoyable online experience, you prefer a single online tool / platform / For a more enjoyable online experience, you prefer a combination of online tools and platforms);

- Perception of the extent to which teachers have adapted (UNPA) - this variable describes the level at which students perceived that their teachers have adapted to the transition to the online environment (In your opinion, teachers have successfully adapted to online teaching).

b) Dependent:

- Online Learning Experience (OLE) - this variable assesses students' satisfaction with online learning. A scale from 1 to 5 was used, where 1 = poor, $5=$ very good (How do you rate the online learning experience?).

\subsection{Multiple linear regression model}

The regression equation underlying the model was as follows:

$$
\begin{aligned}
& \hat{A}=\beta(i . v .1) * i . v .1+\beta(i . v .2) * i . v .2+\beta(i . v .3) * i . v .3++\beta(i . v .4) * i . v .4- \\
& \text { Constant }
\end{aligned}
$$

Where: 
$\hat{O L E}=$ estimated value

$\beta=$ Regression Coefficient

i.v.1 = independent variable $1-\mathrm{UNP}$

i.v. 2 = independent variable $2-\mathrm{UNA}$

i.v.3 $=$ independent variable $3-\mathrm{UNI}$

i.v. 4 = independent variable $4-$ UNPA

At a later stage, the data were tested to see if they had a normal distribution and if we could use the proposed statistical analysis techniques. To determine whether the collected data had a normal distribution, the Shapiro-Wilk test ( $\mathrm{p}>$.05) was performed (Shapiro and Wilk, 1965; Razali and Wah, 2011), then we performed a visual inspection of the normal PP Plot (Figure 1), resulting that the dependent variable OLE (online learning experience) was distributed approximately normally. For the diagnosis of the collinearity statistic we have used the variance inflation factor (VIF). The result of this coefficient determines the existence of multicollinearity by measuring the extent of a correlation between predictors. As it can be seen in Table 1, we have obtained values within the accepted limits VIF $<10$ (Gujarati, 2004; Robinson and Schumacker, 2009). Due to these facts, multiple linear regression analysis was suitable to be performed.

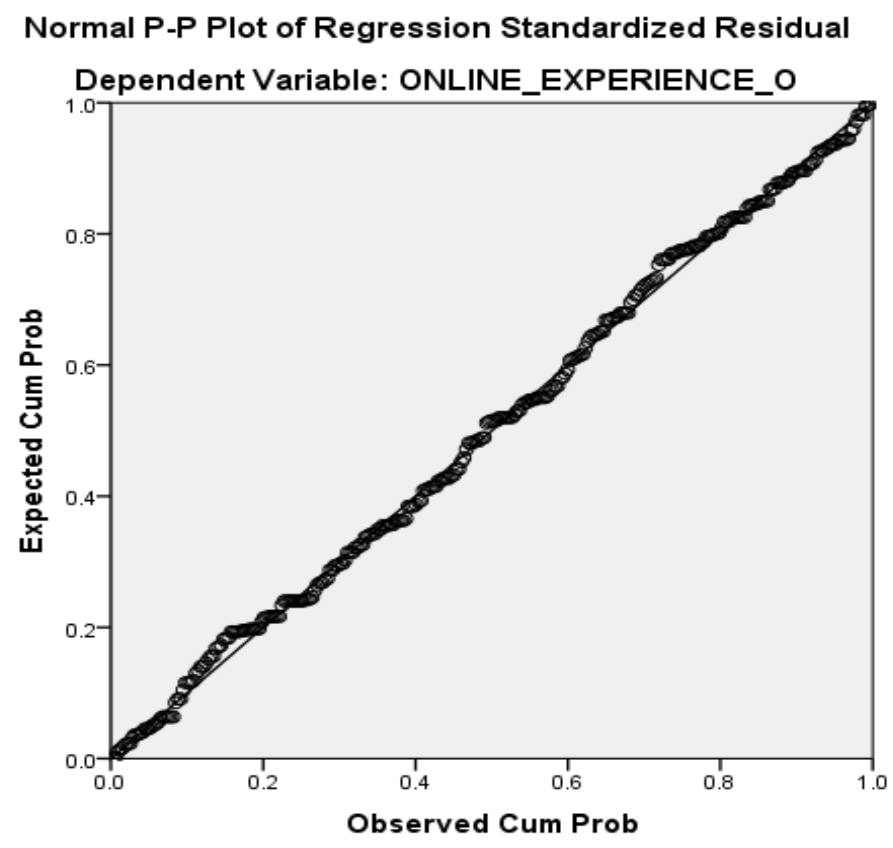

Figure 1. Normal P-P Plot

Source: authors, using IBM SPSS 20

\section{RESULTS AND DISCUSSIONS}

\subsection{The degree of adaptation of the university to the changes imposed by COVID-19}

The COVID-19 pandemic has profoundly affected the university environment, the measures imposed in order to prevent the spread of coronavirus leading to the closure of universities and rethinking the entire teaching-learning process. In this sense, to answer the first question of the research proposed for this research paper, and more precisely to determine the extent to which the university was prepared to move online, students' perceptions of this aspect are illustrated in Figure 2. 


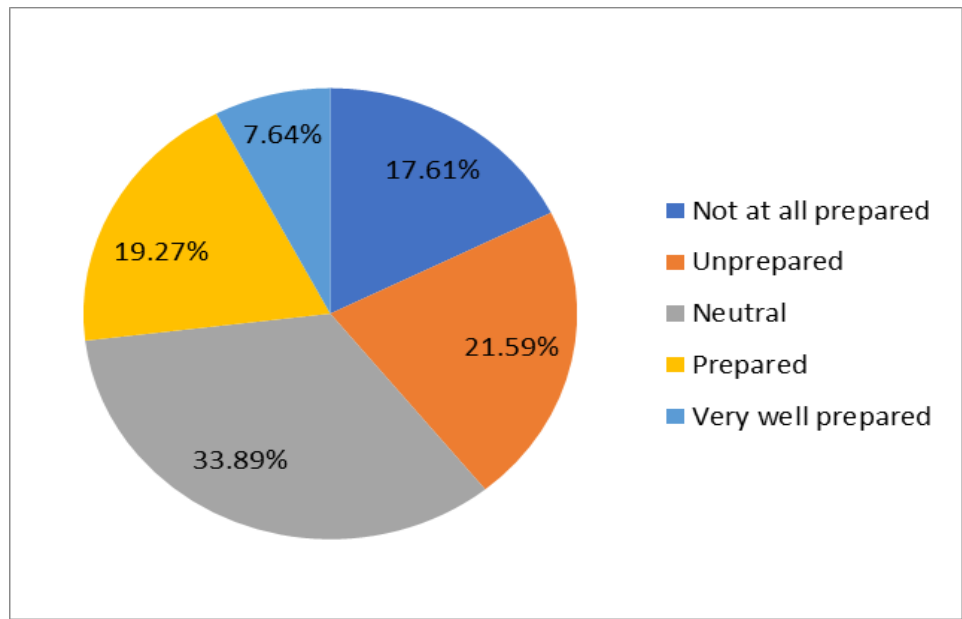

Figure 2. The extent to which the university was prepared to move online Source: Created by the authors based on survey results

Analyzing the results presented in Figure 2, it can be seen that $32.56 \%$ of respondents considered that at the beginning of the pandemic the university was unprepared or not at all prepared, 33.89\% of them were neutral about the extent to which the university was prepared and the remaining $26.91 \%$ considered that the university was prepared for the transition of teaching-learning activities in the online environment. Referring to the differentiation that Rapanta et al. (2020) makes between online education (which presupposes the pre-existence of a certain organizational infrastructure that allows the online development of the teaching-learning process) and emergency remote teaching (which refers to what was needed for the COVID-19 pandemic and it meant for all universities that did not have pre-existing online courses, a quick improvisation, without having a suitable and guaranteed logistical and technological support for this kind of activities), these results show that at the beginning of the pandemic the analyzed university was rather in the second situation.

At the same time, in addition to identifying students' perceptions of the extent to which the university was prepared to deal with the measures imposed by the COVID-19 pandemic, it is relevant to identify students' perceptions of the extent to which the university has adapted to these measures. Thus, regarding the students' perception regarding the extent to which the university in which they study has adapted to the changes imposed by the COVID-19 pandemic, this is highlighted in Figure 3

Figure 3. The extent to which the university has adapted to the changes imposed by COVID-19

Source: Created by the authors based on survey results 
Based on the information illustrated in Figure 3, it can be seen that more than half of the respondents $(50.50 \%)$ consider that the university where they study has adapted well or even very well to the changes imposed by the COVID-19 pandemic and to the online environment. Moreover, $32.89 \%$ of respondents give a neutral answer on this issue and only $16.61 \%$ of respondents believe that the university has failed to adapt properly to the new requirements.

\subsection{The degree of adaptation of teachers to the changes imposed by COVID-19}

In order to provide a comprehensive picture of the effects of the COVID-19 pandemic on the university environment, it is not enough to refer only to the aspects related to the extent to which the university was prepared and adapted, but also to the extent to which teachers adapted to the new requirements.

In the context of the COVID-19 pandemic, teachers faced multiple challenges and had to change their teaching methods and rethink their activities and teaching materials in order to adapt to the requirements of online teaching. Thus, in order to answer the second question of the research, we analyzed the students' perception regarding the extent to which the teachers managed to adapt to the online teaching, the results being presented in Figure 4.

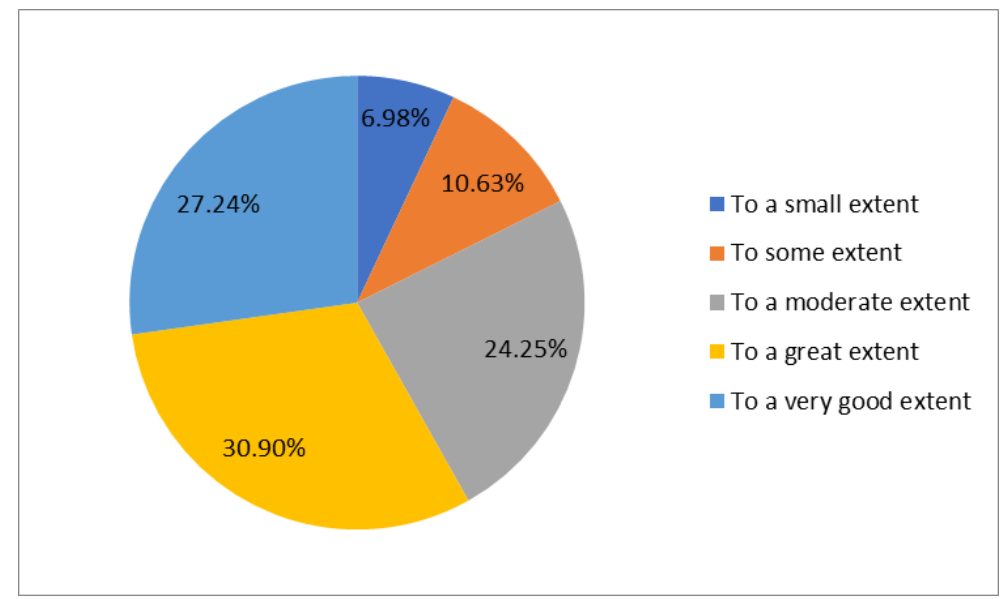

Figure 4. The extent to which teachers have adapted to online teaching

Source: Created by the authors based on survey results

Analyzing the information highlighted in Figure 4, it can be seen that most of the respondents, and more precisely $58.14 \%$ of them, believe that their teachers have adapted to a great and very great extent to online teaching, managing to identify the most appropriate means to facilitate studentteacher interaction and to continue the learning process and development of students.

As already mentioned, the COVID-19 pandemic imposed a series of changes in teaching. Given that lately the courses have taken place more in the online environment, teachers have had to identify several online platforms where to carry out teaching activities. Figure 5 highlights the most used online platforms for student-teacher communication and information exchange. 


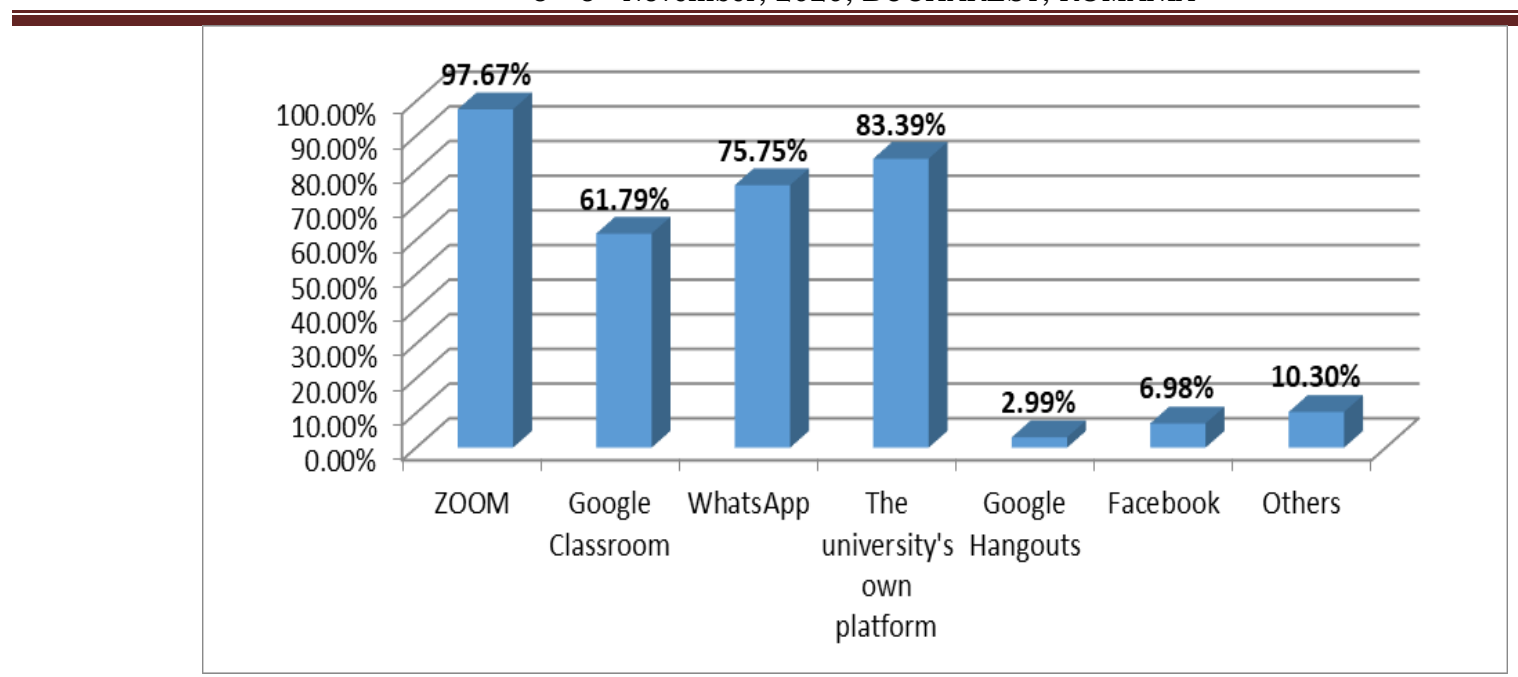

Figure 5. The main online platforms used in the educational process

Source: Created by the authors based on survey results

Analyzing Figure 5, most of the respondents (97.67\%) appreciate that the ZOOM platform is the most often used in teaching activities, this being followed by the university's own platform (83.39\%). Investigating how Romanian society has adapted to the new challenges in education, Edelhauser and Lupu-Dima (2020) show that users in Romania prefer ZOOM software for online activities during COVID-19 because it is free and easy to use, this online platform being mentioned by $73 \%$ of respondents as the platform used for video conferencing courses. Another tool used in the didactic activity mentioned by $75.75 \%$ of the respondents is WhatsApp. Regarding the Google Classroom platform, it is considered by $61.79 \%$ of respondents as being used in the process of communication and exchange of information between students and teachers. According to the share of respondents, other platforms were identified as being used in the educational process, namely Facebook (6.98\%) and Google Hangouts (2.99\%), and also $10.30 \%$ of respondents believe that there are other platforms that are used in carrying out activities (e.g. Discord, Microsoft Teams, etc.).

Following the identification of online platforms used in the educational process, this research aimed to identify students' perceptions of these platforms. Thus, Figure 6 illustrates the degree of appreciation of the respondents concerning the online platforms used by teachers.

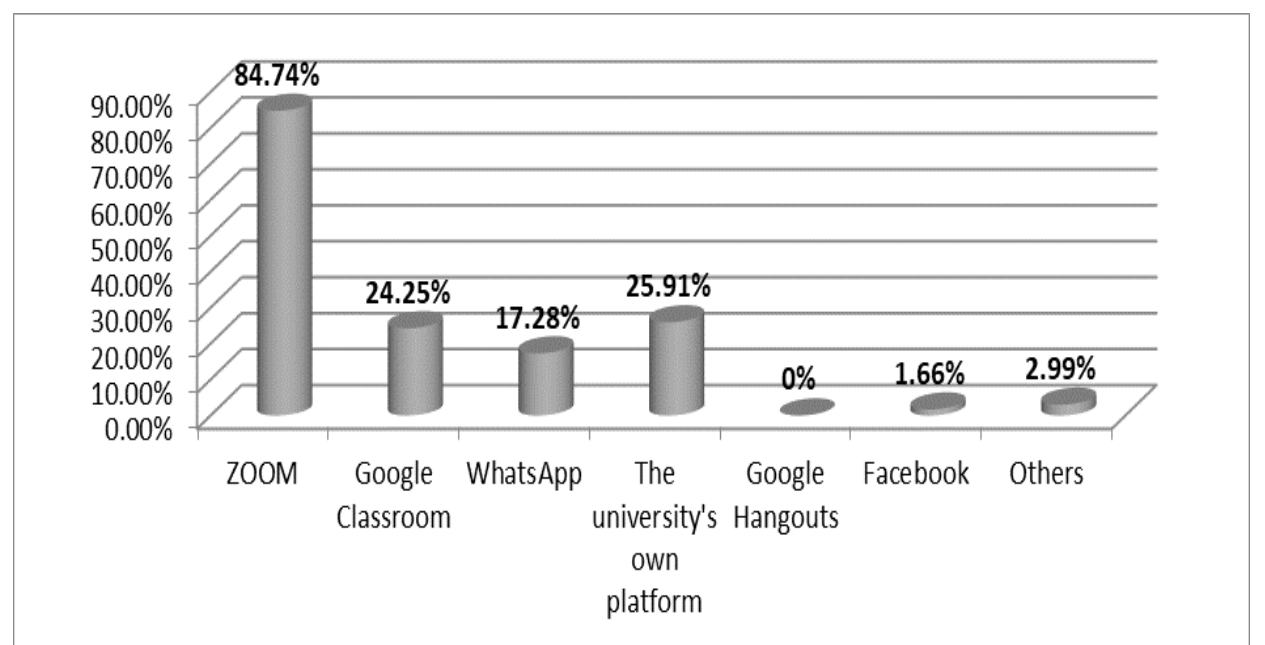

Figure 6. The degree of appreciation of the respondents regarding the online platforms used in the educational process

Source: Created by the authors based on survey results 
Based on the information presented in Figure 6, it can be emphasized that the ZOOM platform is considered by most respondents $(84.74 \%)$ as the best online platform used for communication and exchange of information between teachers and students. The university's own platform is appreciated by $25.91 \%$ of respondents as the best platform used by teachers, and the Google Classroom platform is chosen by $24.25 \%$ of respondents as one of the best platforms used in teaching activities. Other platforms mentioned by students as useful in the educational process are WhatsApp (17.28\%), Facebook (1.66\%) and others (2.99\%).

\subsection{Students' perception of the online learning experience}

With the transition of teaching activities in the online environment, students also found themselves in the situation of adapting to new teaching environments, to identify and learn how to use different online platforms to ensure the continuity of learning and development. Students' perceptions of the online learning experience are shown in Figure 7.

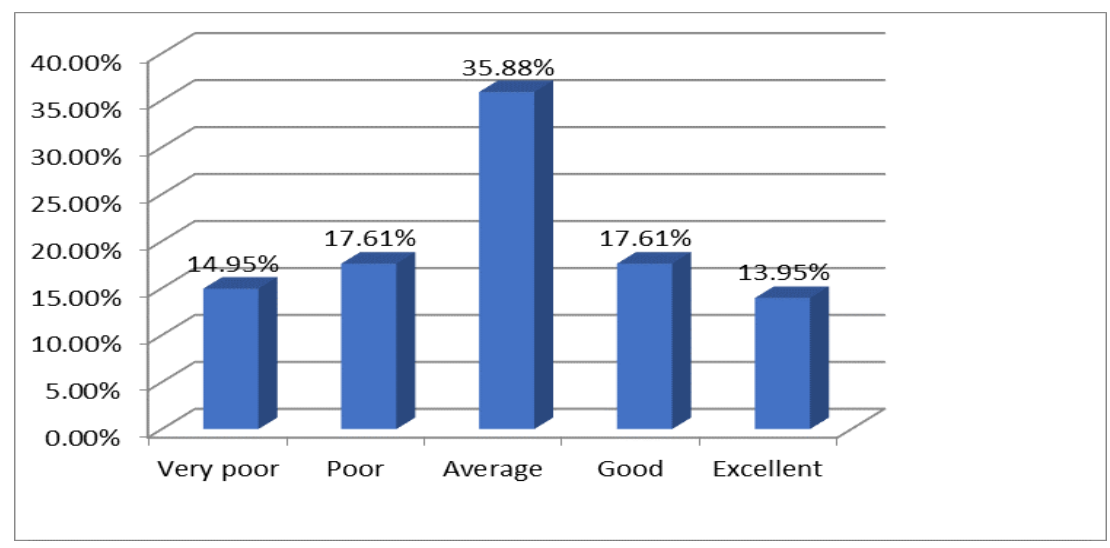

Figure 7. Students' perception of the online learning experience

Source: Created by the authors based on survey results

Asked how they evaluate the online learning experience, based on the information in Figure 7 only $31.56 \%$ of respondents rate the online learning experience as good or very good. $35.88 \%$ of respondents say they are neutral on this issue, while $32.56 \%$ of students rate this experience as poor or very poor. A relevant aspect that deserves attention regarding the students' perception of the online learning experience refers to the fact that in total, the average of this variable $(\mathrm{M}=2.98)$ shows that most are satisfied with the online learning process. Another study conducted in Romania on the transition to digital teaching indicated that most students were satisfied with online education, having a positive learning experience (Veith, 2020).

\subsection{The influences between the degree of adaptation of the university and the professors to the online environment and the online learning experience of the students}

For determining the links between the degree of adaptation of the university and teachers to the online teaching environment and the online learning experience of students, regression analysis was used. The results (Table 1) showed that the R Square for our equation was .316 which indicated that $31.6 \%$ of the variance in OLE was predictable from UNP, UNA, UNI, and UNPA. According to Cohen (2013), this is a moderately strong relationship.

The bootstrapped 95\% confidence interval for the slope to predict OLE from UNP, UNA, UNI, and UNPA ranged from .006 to .290 (UNP); .104 to .439 (UNA); .080 to .266 (UNI) and from .136 to .366 (UNPA). Thus, for each one-unit increase in UNP, OLE increases by about 006 to .290 points; for each one-unit increase in UNA, OLE increases by about .104 to .439 points; for each one-unit increase in UNI, OLE increases by about .080 to .266 points and for each one-unit increase in UNPA, OLE increases by about .136 to .366 points. 
Further, we could observe that the F-test is statistically significant with a 5\% level of significance. That indicates the fact that the independent variables justify the variation on OLE.

Taking into consideration the regression analysis results, the model asserts that UNP, UNA, UNI, and UNPA can describe changes that would appear in OLE.

Table 1. Results for the Multiple Linear Regression

\begin{tabular}{|c|c|c|c|c|c|c|c|}
\hline \multirow[t]{2}{*}{ Variables } & \multirow[t]{2}{*}{$\begin{array}{l}\text { Estimated } \\
\text { Coefficient }\end{array}$} & \multirow{2}{*}{$\begin{array}{l}\text { Standard } \\
\text { Robust } \\
\text { Error }\end{array}$} & \multirow[t]{2}{*}{ VIF } & \multirow[t]{2}{*}{$\begin{array}{c}\text { P- } \\
\text { value }\end{array}$} & \multirow[t]{2}{*}{$\begin{array}{c}\text { Level of } \\
\text { Significance }\end{array}$} & \multicolumn{2}{|c|}{$\begin{array}{c}95 \% \\
\text { Confidence } \\
\text { Interval for B }\end{array}$} \\
\hline & & & & & & $\begin{array}{l}\text { Lower } \\
\text { Bound }\end{array}$ & $\begin{array}{l}\text { Upper } \\
\text { Bound }\end{array}$ \\
\hline UNP - L & .148 & .072 & 2.06 & .041 & ** & .006 & .290 \\
\hline UNA - N & .271 & .085 & 2.35 & .002 & ** & .104 & .439 \\
\hline $\mathbf{U N I}-\mathbf{R}$ & .173 & .047 & 1.03 & .000 & $* *$ & .080 & .266 \\
\hline UNPA - Y & .251 & .058 & 1.40 & .000 & $* *$ & .136 & .366 \\
\hline Constant & .343 & .234 & - & .044 & $* *$ & -.117 & .803 \\
\hline & F-test & $\begin{array}{r}N=30 \\
296)=35 \\
R-s q u a r e d \\
\text { nt had a } 1\end{array}$ & $\begin{array}{l}727(. \\
=316 \\
=.310 \\
6 \text { leve }\end{array}$ & $\begin{array}{l}00) * * \\
\text { of sign }\end{array}$ & ficance & & \\
\hline
\end{tabular}

Source: authors based on collected data

In other words, the multiple linear regression model indicates the following aspects:

$\checkmark$ as the perception that the university is ready to move online grows, students will perceive that the online learning experience is improving;

$\checkmark$ as the perception that the university has adapted well to online education grows, students will perceive that the online learning experience is improving;

$\checkmark$ as students' preference for a combination of e-learning tools increases, they will perceive that the e-learning experience is improving;

$\checkmark$ as the perception that teachers have successfully adapted to online teaching increases, students will perceive that the online learning experience is improving.

\section{CONCLUSION}

The COVID-19 pandemic affected all areas, including education, and once lockdowns were imposed, schools and universities were closed. Therefore, as Rajab et al. (2020) state, online courses have become a priority in education. Although the results of this study show that, from the students' perspective, at the beginning of the pandemic, the university was not ready to move to online teaching-learning, it managed to adapt well and very well to the changes imposed by the COVID-19 pandemic and the transition to the online environment, as mentioned by more than half of the respondents $(50.50 \%)$.

In the context of the measures imposed by the COVID-19 pandemic, teaching-learning activities would not have been possible without the impressive efforts of teachers to adapt to the requirements of online teaching-learning. Regarding the perception of students regarding the extent to which teachers have adopted the changes imposed by COVID -19, the results of this study show that $58.14 \%$ of respondents said that their teachers have adapted to a large and very large extent in online teaching, managing to identify the most appropriate means to facilitate student-teacher interaction and to continue the learning and development process of students. At the same time, through this research it resulted that at the level of the Faculty of Management from Bucharest University of Economic Studies, the most used online platforms for carrying out teaching activities were ZOOM (97.67\%) and the university's own platform (83.39\%). In addition, by analyzing 
students' perceptions of the platforms used in the teaching-learning activities, the results show that the platform most appreciated by students is the ZOOM platform.

Also, the influences identified through the regression model indicated that as students perceived that the university was prepared for such situations and that it adapted well to online learning, their online learning experience became better. Also, the level of adaptation of teachers and the preference for using a combination of online platforms are other factors that directly and positively influence the online learning experience of students.

\subsection{Practical implications and recommendations}

The results of this study bring several contributions, both theoretically and practically. Thus, from a theoretical point of view, this article analyzes a series of challenges faced by universities, professors and students to adapt to the online teaching-learning process, highlighting the degree of perception of students about the extent to which stakeholders in the education system have adapted to the changes imposed by the COVID-19 pandemic.

From a practical point of view, the results of this study can benefit decision makers in the education system because they can help them make the best decisions regarding teaching environments, educational strategies and teaching activities, with a significant impact on students' learning experience. In this sense, in order to improve or maintain a positive perception of students regarding the level of preparation and adaptation of the university, respectively of teachers in the online environment, a precondition is a good choice of the online platform that facilitates the learning process. As the regression analysis has shown, all these perceptions directly and positively influence students' online learning experience. The same analysis indicated that students' preference for a combination of online platforms facilitates a better online experience. However, the average of the variable that described the preference for a single platform or a combination of them was $\mathrm{M}=$ 2.13, which rather indicates a preference for a single platform. These results have a strong impact

from a practical point of view because although students prefer a single tool, in this particular case, their learning experience will improve if they use a combination of online learning tools, mainly because the tool provided by the university (and used by most teachers, being the official one) does not include all the facilities that students consider useful (e.g. audio / video communication), given that ZOOM ranks first in students' preferences. Thus, based on the fact that students prefer a single tool to facilitate online activities and that ZOOM, which is based on audio-video communication occupies the first position in their preferences, and the official platform of the university occupies the second position, the recommendation is to incorporate audio-video facilities into the university's official online platform.

However, until the creation of this unique platform that integrates all the necessary facilities for the effective conduct of online teaching-learning activities, the results of this study may be useful to teachers because it shows that the ZOOM platform is most agreed by students and thus can choose this tool to carry out their activities and facilitate a better online learning experience among students.

\subsection{Limits of research and future directions}

The main limitation of this research is its degree of generalization of the results, given that the study focused on a sample consisting exclusively of one-year students from a single faculty within a single university. Also, the period in which the study was conducted may be another limit, given that the study was conducted in the first months after the onset of the pandemic, a period in which both students and their teachers were in a process of adaptation and discovery of new facilities offered by online learning. Of course, all these limits leave room for future research, which may have a higher degree of generalization and which can be done at a time when the dynamics of adaptation to the online learning process has slowed down. 


\section{REFERENCES}

Boddy, C. R. (2016). Sample size for qualitative research. Qualitative Market Research: An International Journal, 19(4), 426-432. https://doi.org/10.1108/qmr-06-2016-0053.

Cohen, J., Cohen, P., West, S. G., \& Aiken, L. S. (2013). Applied multiple regression/correlation analysis for the behavioral sciences. Routledge.

Dell, R. B., Holleran, S., \& Ramakrishnan, R. (2002). Sample size determination. ILAR journal, 43(4), 207-213. https://doi.org/10.1093/ilar.43.4.207.

Dupont, W. D., \& Plummer Jr, W. D. (1990). Power and sample size calculations: a review and computer program. Controlled clinical trials, 11(2), 116-128. https://doi.org/10.1016/01972456(90)90157-w.

Edelhauser, E., \& Lupu-Dima, L. (2020). Is Romania Prepared for eLearning during the COVID-19 Pandemic? Sustainability, 12(5438). https://doi.org/10.3390/su12135438.

Gujarati, D. N. (2004). Basic Econometrics, Fourth Edition. New York: McGraw-Hill.

Hamade, L. (2020). The Digital Move towards Online Learning in Lebanon. Business Excellence and Management, 10(SI 1), 214-232.

Hill, K., \& Fitzgerald, R. (2020). Student Perspectives on the Impact of COVID-19 on Learning. The All Ireland. Journal of Teaching and Learning in Higher Education (AISHE-J), 12(2), 1-9.

König, J., Jäger-Biela, D. J., \& Glutsch, N. (2020). Adapting to online teaching during COVID-19 school closure: teacher education and teacher competence effects among early career teachers in Germany. European Journal of Teacher Education, 43(4), 608-622. https://doi.org/10.1080/02619768.2020.1809650.

Krejcie, R. V., \& Morgan, D. W. (1970). Determining sample size for research activities. Educational and psychological measurement, 30(3), 607-610.

Mishra, L., Gupta, T., \& Shree, A. (2020). Online teaching-learning in higher education during lockdown period of COVID-19 pandemic. International Journal of Educational Research Open, 2(8). https://doi.org/10.1016/j.ijedro.2020.100012.

Mișu, S. (2020). Teacher's work engagement - change and adaptation during covid-19 pandemic. Business Excellence and Management, 10(SI 1), 243-255.

Osman, M. E. (2020). Global impact of COVID-19 on education systems: the emergency remote teaching at Sultan Qaboos University. Journal of Education for Teaching, https://doi.org/10.1080/02607476.2020.1802583.

Rajab, M. H., Gazal, A. M., \& Alkattan, K. (2020). Challenges to Online Medical Education During the COVID-19 Pandemic. Cureus, 12(7), e8966. https://doi.org/10.7759/cureus.8966.

Ramij, M., \& Sultana, A. (2020). Preparedness of Online Classes in Developing Countries amid COVID-19 Outbreak: A Perspective from Bangladesh. Afrin, Preparedness of Online Classes in Developing Countries amid COVID-19 Outbreak: A Perspective from Bangladesh (June 29, 2020). http://dx.doi.org/10.2139/ssrn.3638718

Rapanta, C., Botturi, L., Goodyear, P., Guàrdia, L., \& Koole, M. (2020). Online university teaching during and after the Covid-19 crisis: Refocusing teacher presence and learning activity. Postdigital Science and Education, 2(3), 923-945. https://doi.org/10.1007/s42438-020$\underline{00155-\mathrm{y}}$

Razali, N. M., \& Wah, Y. B. (2011). Power comparisons of shapiro-wilk, kolmogorov-smirnov, lilliefors and anderson-darling tests. Journal of statistical modeling and analytics, 2(1), 21-33.

Robinson, C., \& Schumacker, R.E. (2009). Interaction Effects: Centering, Variance Inflation Factor, and Interpretation Issues. Multiple Linear Regression Viewpoints, 35(1), 6-11.

Shapiro, S. S., \& Wilk, M. B. (1965). An analysis of variance test for normality (complete samples). Biometrika, 52(3/4), 591-611. https://doi.org/10.2307/2333709

Singh, A. S., \& Masuku, M. B. (2014). Sampling techniques \& determination of sample size in applied statistics research: An overview. International Journal of Economics, Commerce and Management, 2(11), 1-22. 
Veith, C. (2020). Digital Teaching in Romania During COVID 19. In: R. Pamfilie, V. Dinu, L. Tăchiciu, D. Pleșea, C. Vasiliu eds. 6th BASIQ International Conference on New Trends in Sustainable Business and Consumption. Messina, Italy, 4-6 June 2020. Bucharest: ASE, pp. 997-1003.

Weinberg, J. M., \& Kleinman, K. P. (2003). Good study design and analysis plans as features of ethical research with humans. IRB: Ethics \& Human Research, 25(5), 11-14. https://doi.org/10.2307/3564600

WHO. (2020, March 11). WHO Director-General's opening remarks at the media briefing on COVID-19 - 11 March 2020. Retrieved September 19, 2020, from https://www.who.int/director-general/speeches/detail/who-director-general-s-opening-remarksat-the-media-briefing-on-covid-19---11-march-2020

\footnotetext{
${ }^{\mathrm{i}}$ The items that formed the basis of the construction of the independent variables involved the use of an evaluation scale from 1 to 5 , where $1=$ total disagreement and $5=$ total agreement.
} 